\title{
Functional improvements in patients with lymphangioleiomyomatosis after sirolimus: an observational study
}

Yongzhong Zhan ${ }^{1 \dagger}$, Lisha Shen ${ }^{1 \dagger}$, Wenshuai Xu' ${ }^{1}$ Xiuxiu $\mathrm{Wu}^{1}$, Weihong Zhang ${ }^{2}$, Jun Wang ${ }^{1}$, Xue Li $i^{1}$, Yanli Yang ${ }^{1}$, Xinlun Tian ${ }^{1}$ and Kai-Feng $\mathrm{Xu}^{1^{*}}$ (D)

\begin{abstract}
Background: Sirolimus has been shown to be effective in patients with lymphangioleiomyomatosis (LAM). We wish to summarize our experience using sirolimus and its effectiveness in LAM patients.

Methods: We analyzed data from 98 patients who were diagnosed with definite or probable sporadic LAM based on the European Respiratory Society diagnosis criteria for LAM in 2010 at Peking Union Medical College Hospital and who had received sirolimus during January 2007 to June 2015. The data before and after the initiation of sirolimus therapy included pulmonary function tests, arterial blood gas analysis, 6-min walking distance (6MWD), size of chylous effusion and renal angiomyolipomas (AML), St. George's Respiratory Questionnaires (SGRQ) and vascular endothelial growth factor-D (VEGF-D) levels. Serum levels of sirolimus and adverse events were collected.

Results: Median follow-up was 2.5 years. Most patients had forced expiratory volume in $1 \mathrm{~s}\left(\mathrm{FEV}_{1}\right)$ values less than $70 \%$ predicted or symptomatic chylothorax. The mean changes before and after the initiation of sirolimus were $31.12 \pm 30.78 \mathrm{~mL} / \mathrm{month}$ and $16.11 \pm 36.00 \mathrm{~mL} /$ month $(n=18, p=0.002)$ for FEV change, and $-0.55 \pm 0.60 \mathrm{mmHg} /$ month and $0.30 \pm 1.19 \mathrm{mmHg} / \mathrm{month}(n=17, p=0.018)$ for $\mathrm{P}_{\mathrm{a}} \mathrm{O}_{2}$ change. 6MWD improved from $358.8 \pm 114.4 \mathrm{~m}$ to $415.6 \pm 118.6 \mathrm{~m}(n=46, p=0.004)$ and SGRQ total score from $57.2 \pm 21.0$ to $47.5 \pm 22.8(n=50, p<0.001)$. The median VEGF-D concentration decreased to $1609.4 \mathrm{pg} / \mathrm{mL}$ from $3075.6 \mathrm{pg} / \mathrm{mL}$ after sirolimus therapy $(n=41, p<0$. 001). Patients with sirolimus trough levels of $5-9.9 \mathrm{ng} / \mathrm{mL}$ had an increase in $\mathrm{FEV}_{1}(p<0.05)$. Sixty-five percent of patients (13/20) had almost complete resolution of chylous effusions. The most frequent adverse events were mouth ulcers, menstrual disorder, hyperlipidemia and acneiform rash, all were mild.
\end{abstract}

Conclusion: Long-term use of sirolimus is safe in patients with LAM. LAM patients with FEV 1 less than 70\% predicted and symptomatic chylothorax are suitable for receiving sirolimus therapy. The maintaining serum trough levels of sirolimus are recommended between 5 to $9.99 \mathrm{ng} / \mathrm{mL}$.

Keywords: Lymphangioleiomyomatosis, Sirolimus, Pulmonary function, Chylothorax, Adverse events

\section{Background}

Lymphangioleiomyomatosis (LAM) is a rare multisystem neoplastic disorder that mostly afflicts women and primarily affects the lung and kidney [1]. The prevalence of sporadic LAM varies, ranging from 1 to 9 per million women in the general population and $30-40 \%$ of women

\footnotetext{
* Correspondence: kaifeng.xu@gmail.com

${ }^{\dagger}$ Equal contributors

'Department of Respiratory Medicine, Peking Union Medical College

Hospital, Beijing, China

Full list of author information is available at the end of the article
}

with tuberous sclerosis complex (TSC) [2, 3]. Patients with LAM suffer from worsening dyspnea and an increasing number of cysts by computed tomography (CT) detection. Forced expiratory volume in $1 \mathrm{~s}\left(\mathrm{FEV}_{1}\right)$, one of the most important pulmonary function measurements, declines at a rate of 75 to $134 \mathrm{~mL}$ per year $[4,5]$. The management of LAM, however, focuses on observation and supportive therapy. Few effective medications have been identified to slow disease progression.

Loss of TSC2 gene expression plays a central role in the pathogenesis of LAM [6]. The TSC1/TSC2 complex 
persistently activates the mammalian target of rapamycin (mTOR) signaling pathway, which regulates cellular metabolism, growth and survival. Sirolimus (also called rapamycin), an mTOR inhibitor, maintains mTOR downstream signals and multiple cellular functions at appropriate levels [7]. Sirolimus has been shown to be efficacious in sporadic LAM and TSC-associated patients regarding lung function, lymphatic disease and renal angiomyolipomas in previous studies, including the Multicenter International Lymphangioleiomyomatosis Efficacy and Safety of Sirolimus (MILES) trial [5, 8-14]. These studies have provided evidence for using sirolimus in LAM patients with moderately severe lung disease, chylothorax, chylous ascites or renal angiomyolipomas. In Peking Union Medical College Hospital (PUMCH), sirolimus has been used in LAM patients since 2007, and much data have been accumulated during this period. This study was aimed at summarizing our experience and providing more evidence regarding the safety, indication, timing and dose of sirolimus.

\section{Methods}

\section{Study population}

We reviewed records from patients at PUMCH between January 2007 and June 2015. The patients were included if they 1) were diagnosed with definite or probable LAM, based on the European Respiratory Society (ERS) guidelines in 2010 [15] and 2) received sirolimus treatment for at least 12 months. Patients with TSCassociated LAM were excluded in this analysis. The study was part of the LAM registry study of PUMCH. The protocol was approved by the Ethical Committee of PUMCH (S-379). All subjects included in this study signed informed consent documents.

\section{Medication use}

Most patients included in this study followed common rules to adjust their sirolimus dose. The initial dose was $2 \mathrm{mg}$ per day if the patient weighed $\geq 50 \mathrm{~kg}$ and $1 \mathrm{mg}$ per day if the patient weighed $<50 \mathrm{~kg}$. The patients were advised to perform a concentration test one month after the initiation of sirolimus. A serum level of 5 to $9.9 \mathrm{ng} /$ $\mathrm{mL}$ sirolimus was the target range. Patients with a sirolimus concentration $\geq 10 \mathrm{ng} / \mathrm{mL}$ were recommended to reduce the dose by half. For patients with serum levels $<5 \mathrm{ng} / \mathrm{mL}$, if the clinical symptoms were improving according to a physician's evaluation, the initial dose was continued; if not, the dose of sirolimus was adjusted. After adjustment of the sirolimus dose, the concentration test and symptom evaluation were repeated every 1 to 3 months. The dose of sirolimus was also adjusted due to adverse events or cost burden.

\section{Study design}

The records of the included patients were carefully reviewed. We collected the following data: pulmonary function tests, arterial blood gas analysis at rest (on room air), six-minute walking distance (6MWD), St. George's Respiratory Questionnaire (SGRQ), vascular endothelial growth factor-D (VEGF-D), and response rate of the chylothorax and presence of renal angiomyolipomas by radiological evaluation. We defined baseline data as those collected within 30 days of sirolimus initiation, and additional data were collected 6 months ( \pm 3 months), 12 months ( \pm 3 months) and $\geq 15$ months after sirolimus initiation. The rate of change in each parameter per month was calculated with data from the most remote two points and time duration. The response of the chylothorax was defined as almost no effusion present on any kind of imaging examination, including chest X-ray, CT and ultrasound, after 6 months without any other interventional or surgical procedures. Adverse events were defined as symptoms that appeared after the therapy was initiated and that lasted for at least 2 days or resulted in abnormal laboratory findings.

Pulmonary function tests were performed according to the ATS/ERS Task Force Standardization of Lung Function Testing in 2005 [16]. The six-minute walking tests were evaluated based on ATS Guidelines for the sixminute walk test [17]. The SGRQs were completed by patients according to the provided instructions [18]. The chylothorax was evaluated by chest X-ray or CT. Renal angiomyolipoma size was evaluated by $\mathrm{CT}$ (plain or contrast-enhanced). All imaging was done in a radiology department and interpreted by both radiologists and respiratory physicians. Serum VEGF-D levels were tested by enzyme-linked immunosorbent assay (R\&D Systems).

\section{Statistical analysis}

The normality of the data was analyzed by KolmogorovSmirnov test. Data in normal distribution were reported as means $\pm \mathrm{SD}$ and data in non-normal distribution were reported as median (Q1, Q3). Paired and unpaired $T$ tests were used to compare the differences before and after treatment. All reported $p$ values are two-sided. $p$ values of less than 0.05 were considered statistically significant. All analyses were performed using SPSS software, version 20.0 (IBM, USA).

\section{Results}

\section{Patient characteristics}

From January 2010 to June 2015, 231 patients were diagnosed with definite or probable sporadic LAM in $\mathrm{PUMCH}$. Of these, 98 patients were enrolled into this study according to the inclusion and exclusion criteria. The number of definite LAM patients was 70 , and the number of probable LAM patients was 28 . The clinical 
characteristics of these patients are shown in Table 1 . The most frequent reasons for starting sirolimus therapy was $\mathrm{FEV}_{1}$ less than $70 \%$ predicted. Four patients started sirolimus for early treatment; three of these patients had

Table 1 Baseline demographic and clinical characteristics of patients with lymphangioleiomyomatosis

\begin{tabular}{|c|c|}
\hline Characteristics & Numbers (\%) \\
\hline Patients numbers & 98 \\
\hline Age-year & $21-62$ \\
\hline \multicolumn{2}{|l|}{ Gender } \\
\hline Female & $98(100)$ \\
\hline \multicolumn{2}{|l|}{ Race } \\
\hline Asian & $98(100)$ \\
\hline \multicolumn{2}{|l|}{ Diagnosis } \\
\hline Definite LAM & 78 (79.6) \\
\hline Probable LAM & $20(20.4)$ \\
\hline \multicolumn{2}{|l|}{ Clinical features } \\
\hline Postmenopause & $5(5.1)$ \\
\hline Previous pregnancy & $76(77.6)$ \\
\hline Former smoker & $0(0)$ \\
\hline Renal angiomyolipomas & 19 (19.4) \\
\hline Retroperitoneal angiomyolipomas & $2(2.0)$ \\
\hline History of pneumothorax & $42(42.8)$ \\
\hline History of chylothorax & $35(35.7)$ \\
\hline \multicolumn{2}{|l|}{ Pulmonary-functions ${ }^{\mathrm{a}}$} \\
\hline $\mathrm{FEV}_{1}(\mathrm{~L})$ & $1.51 \pm 0.74$ \\
\hline $\mathrm{FEV}_{1} /$ pred (\%) & $49.03 \pm 24.64$ \\
\hline $\mathrm{FVC}(\mathrm{L})$ & $2.55 \pm 0.74$ \\
\hline FVC/pred (\%) & $76.31 \pm 22.99$ \\
\hline $\mathrm{FEV}_{1} / \mathrm{FVC}(\%)$ & $51.22 \pm 16.53$ \\
\hline $\mathrm{PaO}_{2}$ on room air $(\mathrm{mmHg})$ & $65.26 \pm 11.39$ \\
\hline \multicolumn{2}{|l|}{ Reasons for sirolimus-No. (\%) } \\
\hline $\mathrm{FEV}_{1}$ less than $70 \%$ predicted & $65(66.3)$ \\
\hline Chylothorax or other lymphatic manifestations $^{\mathrm{b}}$ & $22(22.4)$ \\
\hline Renal angiomyolipoma & $4(4.1)$ \\
\hline Early treatment ${ }^{c}$ & $4(4.1)$ \\
\hline Unknown reasons $^{d}$ & $3(3.1)$ \\
\hline \multicolumn{2}{|l|}{ Types of sirolimus used ${ }^{e}$} \\
\hline Rapamune & $76(77.6)$ \\
\hline Yixinke & $21(21.4)$ \\
\hline Saimosi & $1(1.0)$ \\
\hline
\end{tabular}

Abbreviations: LAM lymphangioleiomyomatosis, $F E V_{1}$ forced expiratory volume in $1 \mathrm{~s}$ aSample size for spirometry and blood gas analysis was 71 and 81 respectively bincluding measurable lymphangiomyomas, lymphangiectasis and lymphedema

Including 3 patients with $\mathrm{FEV}_{1}$ annual decreases of more than $90 \mathrm{~mL}$ and 1 patient with normal and stable $\mathrm{FEV}_{1}$

${ }^{d}$ Reason for sirolimus could not be identified because of insufficient data eRapamune, Pfizer Pharmaceuticals Ltd.; Yixinke, North China Pharmaceuticals Co., Ltd.; Saimosi, Hangzhou Sino-American Pharmaceuticals Ltd rapidly declining pulmonary function, which presented as $\mathrm{FEV}_{1}$ decreasing by more than $90 \mathrm{~mL}$ per year but still within the normal range. Another patient had normal and stable pulmonary function. Some patients (3.1\%) were treated with sirolimus for unknown reasons because of insufficient data. Median follow-up was 2.5 $(2.0,4.0)$ years.

\section{Sirolimus improves $\mathrm{FEV}_{1}$ of pulmonary function tests}

The rates of change in pulmonary function variables before sirolimus could be obtained for 38 patients $(-22.20$ $\pm 26.07 \mathrm{ml} / \mathrm{month}$ ), and the rates of change after sirolimus could be obtained for 34 patients $(12.23 \pm 31.54 \mathrm{ml} /$ month). In 18 patients, the change rates both before and after sirolimus treatment were obtained. In paired comparisons, the mean monthly changes of $\mathrm{FEV}_{1}$ were $31.12 \pm 30.78 \mathrm{~mL}$ and $16.11 \pm 36.00 \mathrm{~mL}$, respectively ( $p$ $=0.002$ ) (Table 2, Fig. 1). $\mathrm{FEV}_{1} \%$ of predicted value, FVC\% of predicted value, $\mathrm{FEV}_{1} / \mathrm{FVC}$ and $\mathrm{DL}_{\mathrm{CO}} \%$ of predicted value were also improved significantly in paired comparisons (Table 2). Unpaired comparisons before sirolimus and after sirolimus showed similar results except insignificant changes of $\mathrm{DL}_{\mathrm{CO}}$ (data not shown).

The $\mathrm{FEV}_{1}$ value, $\mathrm{FEV}_{1} \%$ of predicted value, $\mathrm{FVC} \%$ of predicted value for the patients were significantly increased after 6 months and $\geq 15$ months on sirolimus relative to the baseline levels $(p<0.05)$. These variables also increased after 12 months of sirolimus therapy, but these changes were not statistically significant (Table 3 ).

Table 2 Effects of sirolimus on rates of change in pulmonary function and arterial blood gas

\begin{tabular}{|c|c|c|c|}
\hline \multirow[t]{2}{*}{ 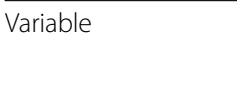 } & \multicolumn{3}{|c|}{ Change per month (Paired) } \\
\hline & Before sirolimus & After sirolimus & $P$ value \\
\hline Pulmonary Function & $(N=18)$ & & \\
\hline $\mathrm{FEV}_{1}(\mathrm{~mL})$ & $-31.12 \pm 30.78$ & $16.11 \pm 36.00$ & 0.002 \\
\hline $\mathrm{FEV}_{1} /$ pred (\%) & $-0.95 \pm 0.82$ & $0.30 \pm 0.89$ & $<0.001$ \\
\hline FVC/pred (\%) & $-1.13 \pm 0.93$ & $0.71 \pm 1.36$ & 0.001 \\
\hline $\mathrm{FEV}_{1} / \mathrm{FVC}(\%)$ & $-0.82 \pm 1.36$ & $0.78 \pm 2.16$ & 0.019 \\
\hline RV/pred (\%) & $2.50 \pm 9.01$ & $0.16 \pm 8.30$ & 0.497 \\
\hline TLC/pred (\%) & $1.02 \pm 4.49$ & $1.15 \pm 6.20$ & 0.953 \\
\hline RV/TLC (\%) & $0.78 \pm 2.38$ & $0.41 \pm 2.58$ & 0.688 \\
\hline $\mathrm{DL}_{\mathrm{co}} /$ pred $(\%)$ & $-0.72 \pm 1.34$ & $1.10 \pm 2.28$ & 0.043 \\
\hline Arterial Blood Gas & $(N=17)$ & & \\
\hline $\mathrm{P}_{\mathrm{a}} \mathrm{O}_{2}(\mathrm{mmHg})$ & $-0.55 \pm 0.60$ & $0.30 \pm 1.19$ & 0.018 \\
\hline $\mathrm{P}_{\mathrm{a}} \mathrm{CO}_{2}(\mathrm{mmHg})$ & $0.005 \pm 0.327$ & $0.058 \pm 0.194$ & 0.170 \\
\hline $\mathrm{P}_{(\mathrm{A}-\mathrm{a})} \mathrm{O}_{2}(\mathrm{mmHg})$ & $0.31 \pm 0.92$ & $-0.75 \pm 1.28$ & 0.037 \\
\hline
\end{tabular}

Abbreviations: $F E V_{1}$ forced expiratory volume in $1 \mathrm{~s}, F V C$ forced vital capacity, $R V$ residual volume, $T L C$ total lung capacity, $D L_{c o}$ diffusing capacity for carbon monoxide, $\mathrm{P}_{a} \mathrm{O}_{2}$ partial pressure of oxygen in arterial blood, $\mathrm{P}_{a} \mathrm{CO}_{2}$ partial pressure of carbon dioxide in arterial blood, $P_{(A-a)} O_{2}$ alveolar-arterial oxygen gradient

Data are presented as mean $\pm S D$ 


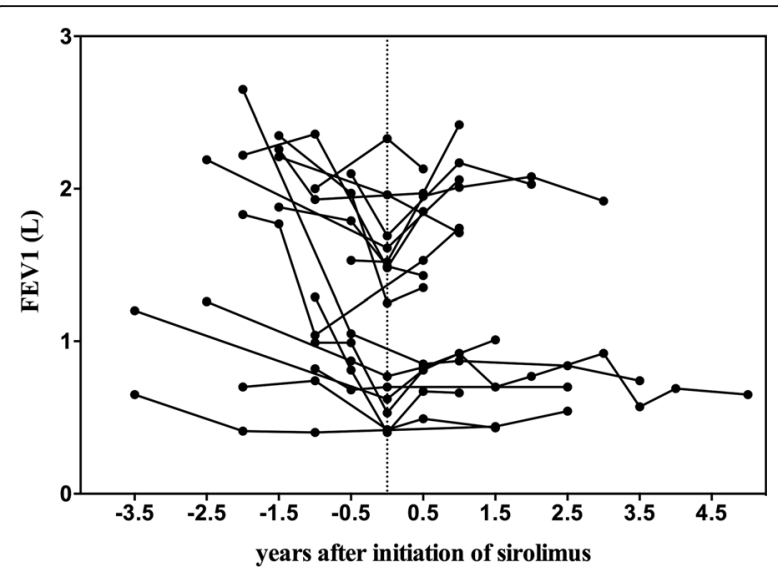

Fig. 1 Change in $\mathrm{FEV}_{1}$ before and after sirolimus in paired groups. Zero on the horizontal axis indicates the day on which sirolimus therapy was initiated; negative and positive numbers indicate years before and after the initiation of sirolimus administration, respectively. Abbreviations: $\mathrm{FEV}_{1}$, forced expiratory volume in $1 \mathrm{~s}$

Some patients had $\mathrm{FEV}_{1}$ values above their baseline values after 6 months $(85.7 \%, 12 / 14)$, whereas the remaining patients $(14.3 \%, 2 / 14)$ showed slight decreases relative to their baseline $\mathrm{FEV}_{1}$ values. All nine patients had $\mathrm{FEV}_{1}$ values greater than (8/9) or equal to $(1 / 9)$ baseline levels after more than 15 months on sirolimus.

Four patients were considered as having received early treatment. One patient was in a normal and stable state of lung function and did not have any other obvious manifestations when she started sirolimus therapy. This was a 56-year-old woman who maintained normal pulmonary function test results three years after initiating sirolimus and seven years after receiving a diagnosis of LAM. An additional three patients also had normal pulmonary function tests but showed trends towards rapidly declining $\mathrm{FEV}_{1}$ (>90 mL per year). Two of these patients were able to reach stable lung function during sirolimus therapy. The $\mathrm{FEV}_{1}$ of the remaining patient decreased by $130 \mathrm{~mL}$ per year before sirolimus and $250 \mathrm{~mL}$ per year after sirolimus.

\section{Sirolimus improves the oxygen level}

Sirolimus significantly improved the arterial oxygen levels and alveolar arterial oxygen gradient according to the rates of change (Table 2) and absolute values at different time points after the therapy (Table 3). When compared with baseline measurements, $71.4 \%(15 / 21)$, $75 \%(12 / 16)$ and $85.7 \%(12 / 14)$ of the patients had higher $\mathrm{P}_{\mathrm{a}} \mathrm{O}_{2}$ after 6,12 and $\geq 15$ months on sirolimus. In total, $\mathrm{P}_{\mathrm{a}} \mathrm{O}_{2}$ was $5 \mathrm{mmHg}$ higher on average after sirolimus treatment than at baseline.
Sirolimus improves the 6-min walking distance (6MWD) In a paired group analysis $(n=46)$, the $6 \mathrm{MWD}$ was $358.8 \pm 114.4 \mathrm{~m}$ before sirolimus and $415.6 \pm 118.6 \mathrm{~m}$ after sirolimus $(p<0.05)$. The mean increase was $56.8 \mathrm{~m}$. The 6MWD results after 6 months, 12 months and $\geq 15$ months on sirolimus increased significantly compared with baseline data $(p<0.05)$.

\section{Sirolimus improves the resolution of chylothorax}

Twenty patients started sirolimus therapy because of symptomatic chylothorax, and two of these patients were complicated with chylous ascites. Chylous effusions had been present $1.72 \pm 2.17$ years before the initiation of sirolimus therapy. Before sirolimus therapy, all patients had undergone thoracentesis, and 6 patients had required chest tube drainage. Surgical intervention had been performed in 7 of the 20 patients, including pleurodesis in 3 patients, lymphatic venous anastomosis in 3 patients, ligation of the thoracic duct in 1 patient and lysis of thoracic duct adhesions in 1 patient. One of these patients had undergone both pleurodesis and lymphatic venous anastomosis. These interventions, however, did not prevent the recurrence of pleural effusions in any patient. During sirolimus therapy, 13 patients had almost complete resolution of their pleural effusions, and the response rate reached $65 \%$. Two patients still experienced chylous effusions during sirolimus therapy and required thoracentesis. The results of another 5 patients could not be found in our database.

Two patients started sirolimus therapy for severe lymphatic manifestations and experienced relief during the therapy. One patient was a 34-year-old woman who had her retroperitoneal lymphangiomyoma resected in 2006 and found it recurrent and progressing in size (the maximum diameter was $2.9 \mathrm{~cm}$ ) in 2012. During sirolimus therapy (2012 to present), the mass decreased and disappeared on abdominal CT in 2016. The other patient, a 44-year-old woman, had multiple retroperitoneal lymphangiomyomas and lymphangiectasis and severe lymphedema in her left lower extremity without chylous effusions or ascites in 2012 and initiated sirolimus at that time. She also experienced relief from the lymphatic manifestations during follow-up.

\section{Effects of sirolimus on angiomyolipomas}

Of the 19 patients with renal angiomyolipomas, 11 had angiomyolipomas diameter more than $1 \mathrm{~cm}$. We had follow-up data to 2015 in 6 patients and 5 of them had a decrease in tumor diameter after sirolimus therapy. Another one had her mass resected before initiating sirolimus and did not got any recurrence during sirolimus therapy, for 14 months in data. 2 patients had retroperitoneal angiomyolipomas in their history. One of them had it resected before sirolimus therapy and did not have 


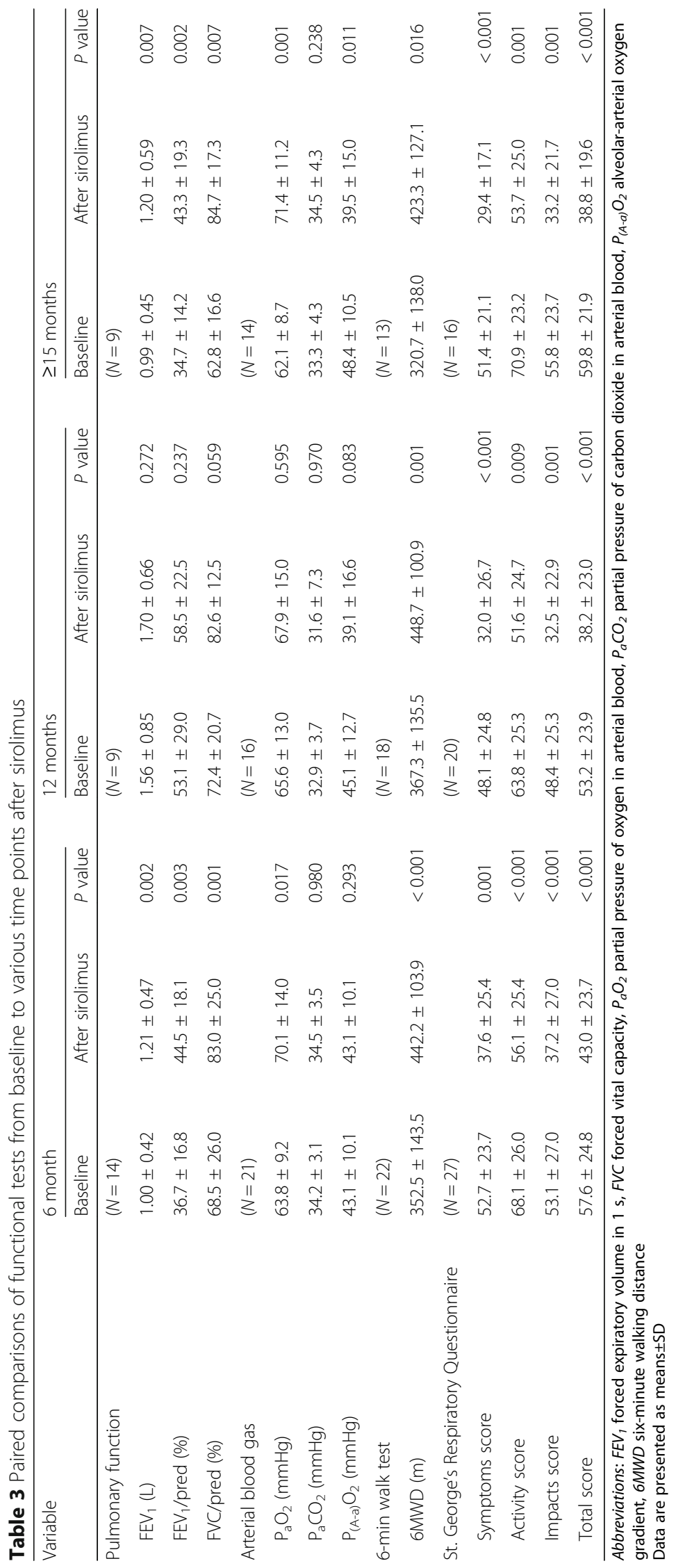


any recurrence during sirolimus therapy, for 18 months in data. Another one did not undergo follow-up abdominal CT.

\section{Sirolimus improves the quality of life (SGRQ score)}

In paired groups $(n=50)$, symptom scores, activity scores, impact scores and total scores of SGRQ after sirolimus therapy all exhibited significant decrease from the baseline value of $51.2 \pm 21.8,67.1 \pm 21.0,52.7 \pm 23.4$ and $57.2 \pm 21.0$ to the after treatment value of $41.0 \pm 25.1,59.9$ $\pm 23.5,42.3 \pm 25.0$, and $47.5 \pm 22.8$ respectively $(p<0.05)$. The mean decrease in SGRQ total scores was 9.7. SGRQ scores at 6 months, 12 months and 15 months after initiation of sirolimus therapy all declined significantly compared with baseline data $(p<0.05)$ (Table 3).

\section{Effects of sirolimus on serum VEGF-D concentrations} The median serum VEGF-D concentration was $3075.6 \mathrm{pg} / \mathrm{mL}(2406.5 \mathrm{pg} / \mathrm{mL}, 4359.6 \mathrm{pg} / \mathrm{mL})$ before sirolimus and $1609.4 \mathrm{pg} / \mathrm{mL}(1162.1 \mathrm{pg} / \mathrm{mL}, 2457.1 \mathrm{pg} / \mathrm{mL})$ after sirolimus $(n=41, p<0.05)$. Baseline VEGF-D levels may predict treatment response of oxygen levels. When patients were divided to two groups based on $\mathrm{P}_{\mathrm{a}} \mathrm{O}_{2}$ changes after treatment $(<0.3 \mathrm{mmHg} /$ month, $n=20$ and $\geq 0.3 \mathrm{mmHg} /$ month, $\mathrm{n}=20$ ), significant difference of baseline VEGF-D levels, 2665.7 (1723.4, 3144.9) pg/ml and $4589.5(2140.0,3475.5) \mathrm{pg} / \mathrm{ml}$ respectively, was found $(p<0.05)$. There was no difference of baseline VEGF-D levels in two groups based on $\mathrm{FEV}_{1}$ changes after treatment $(<4 \mathrm{ml} / \mathrm{month}, n=14$ and $\geq 4 \mathrm{ml} /$ months, $n=16$ ).

\section{Serum levels of sirolimus}

The serum levels of sirolimus were tested at PUMCH in 59 patients. Most patients (72.9\%) maintained sirolimus levels between 5 to $9.9 \mathrm{ng} / \mathrm{mL}$. Some patients (20.3\%) had sirolimus levels under $5 \mathrm{ng} / \mathrm{mL}$ but all above $3 \mathrm{ng} /$ $\mathrm{mL}$. Patients with sirolimus trough levels $5-9.9 \mathrm{ng} / \mathrm{mL}$ had significant increases in $\mathrm{FEV}_{1}(p<0.05)$. Patients with low-dose sirolimus (trough levels $3-4.9 \mathrm{ng} / \mathrm{mL}$ ) and relatively high-dose (trough levels $10-14.9 \mathrm{ng} / \mathrm{mL}$ ) showed only a tendency to an increase in $\mathrm{FEV}_{1}$, but the increase was not statistically significant $(p>0.05)$.

\section{Adverse events potentially related to sirolimus}

The most common adverse events were mouth ulcers, menstrual disorder, hyperlipidemia and acneiform rash (Table 4). Almost all adverse events were mild. Only three patients discontinued sirolimus due to severe adverse events, which included elevated liver enzymes, lung infection and fever. All three patients initiated the therapy again after 2 to 6 months and were free of severe adverse events.
Table 4 Adverse events in patients with sirolimus ${ }^{a}$

\begin{tabular}{lll}
\hline Adverse events & Number of patients & Percentage (\%) \\
\hline Mouth ulcers & 43 & 43.9 \\
Menstrual abnormality & 26 & 26.5 \\
Hyperlipidemia & 15 & 15.3 \\
Acneiform rash & 15 & 15.3 \\
Diarrhea & 2 & 2.0 \\
Fever & 2 & 2.0 \\
Peripheral edema & 2 & 2.0 \\
Gingival hyperplasia & 2 & 2.0 \\
Infections & 1 & 1.0 \\
Hypertension & 1 & 1.0 \\
Non-productive cough & 1 & 1.0 \\
Nasal allergy & 1 & 1.0 \\
Low back pain & 1 & 1.0 \\
Chest pain & 1 & 1.0 \\
Alopecia & 1 & 1.0 \\
Toothache & 1 & 1.0 \\
Arthralgia (finger) & 1 & 1.0 \\
Dizziness & 1 & 1.0 \\
Palpitation & 1 & 1.0 \\
Elevated alanine aminotransferase & 1 & 1.0 \\
\hline Three & &
\end{tabular}

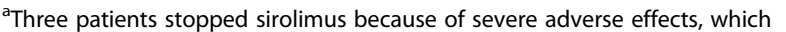
were elevated liver alanine aminotransferase, lung infection and fever. All of them initiated the therapy again after 2 to 6 months and were free of severe adverse events

\section{Discussion}

In the present study, LAM patients, most of whom had damaged pulmonary function and lymphatic manifestations, benefited from sirolimus therapy without severe adverse events. Sirolimus stabilized pulmonary function and arterial partial oxygen pressure, improved quality of life and exercise tolerance, and induced remission of lymphatic manifestations, especially chylothorax. Sirolimus also reduced serum levels of the disease severity associated biomarker VEGF-D.

For functional evaluation, pulmonary function variables are the most direct way to determine the efficacy of sirolimus. Before sirolimus therapy, the patients were experiencing losses in $\mathrm{FEV}_{1}$ of $266.40 \mathrm{~mL}$ per year, which was 8.8 times that of the annual loss in healthy people [19]. After sirolimus treatment, $\mathrm{FEV}_{1}$ was remarkably improved to adding $146.76 \mathrm{ml}$ per year that was higher than previous reports $[5,8,10]$.

In addition to the patients with severely impaired lung function, we also looked on those patients who had relatively normal lung function. An annual loss of $90 \mathrm{~mL}$ or more in the $\mathrm{FEV}_{1}$ value was considered rapidly declining as this is three-fold greater than the normal rate of annual loss in healthy people $[19,20]$. Two patients out of 
three eliminated the $\mathrm{FEV}_{1}$ rapid loss during sirolimus therapy, which reminded us to pay more attention to the declining rate rather than the absolute value of lung function. Another patient who started sirolimus with normal and stable lung function and had persistently stable $\mathrm{FEV}_{1}$ during sirolimus provided physicians with a choice of initiating sirolimus at the time of diagnosis so that the patient's lung function could be stabilized as early as possible.

Patients evaluated after 15 months of sirolimus therapy still showed stabilization of lung function, which indicated that sirolimus had a sustained effect on the LAM patients. The importance of the observed changes in lung function was further supported by arterial blood gas analysis, 6MWD and SGRQ scores. These results were consistent with those from two long-term observational studies $[8,11] . \mathrm{P}_{\mathrm{a}} \mathrm{O}_{2}$ is a comprehensive manifestation of ventilation and gas exchange function, both of which are damaged in LAM patients. Actually, the positive change in $\mathrm{P}_{\mathrm{a}} \mathrm{O}_{2}$ was in accordance with other variables associated with lung function, indicating that it was also an effective evaluation measurement. The 6MWD was stabilized but not improved after sirolimus in the MILES trial [5]. In another observation of only 5 patients, 6MWD significantly improved after sirolimus [21]. The patients in our study showed a significant increase of $57 \mathrm{~m}$, which demonstrated the sirolimusrelated effects on exercise tolerance. SGRQ was used in our study to evaluate the quality of life, representing overall status of health of patients. Our results suggested SGRQ was sensitive showing treatment response after sirolimus. In our previous study, we found SGRQ is correlated with Borg scale of breathlessness, 6MWD, oxygen and pulmonary functions in LAM patients [22]. Quality of life improvement after sirolimus was also reported in MILES study evaluated with EuroQoL visualanalogue scale and Functional Performance Inventory [5]. MILES study also confirmed the correlations of SGRQ and $\mathrm{FEV}_{1}, \mathrm{DL}_{\mathrm{CO}}$, and 6MWD [23]. Exercise capacity and health-related quality of life are important outcomes in LAM patients.

At least $65 \%$ of the patients (13/20) who had symptomatic chylothorax had favorable responses to sirolimus in our study. Taveira-DaSilva reported that all 12 patients with chylous effusions experienced resolution of this condition, and 9 of these patients had complete resolution [10]. Another study showed that chylothorax resolved completely within 1 to 5 months of sirolimus therapy in 6 of 7 cases. Several case reports have also supported the effectiveness of sirolimus in the remission of chylous effusions [24-28].

With respect to dosing, the sirolimus dose was generally adjusted to maintain a serum trough level between 5 and $15 \mathrm{ng} / \mathrm{mL}[5,10,11,29]$. A Japanese and a recent
United Kingdom study suggested that low-dose sirolimus, which resulted in serum trough levels lower than $5 \mathrm{ng} / \mathrm{mL}$, was also effective in stabilizing lung function and resolving chylothorax $[9,30]$. In our study, however, patients with low-dose sirolimus (trough levels 3$4.9 \mathrm{ng} / \mathrm{mL}$ ) showed increases in $\mathrm{FEV}_{1}$, but this change was not statistically significant $(p>0.05)$. We should pay attention to the fact that the number of patients was small $(n=5)$. Interestingly, adjusting sirolimus dose to serum trough levels being 5-9.9 $\mathrm{ng} / \mathrm{mL}$, but not 5$15 \mathrm{ng} / \mathrm{mL}$, was effective enough to improve lung function in LAM patients.

This study described our experience of using sirolimus in a real practice with LAM patients. There are several limitations. The follow-up evaluations were not comprehensive due to irregular follow-up, unwillingness to be evaluated, or inability to be evaluated due to health status or medical costs. Second, the sample sizes in some subgroup analyses were small. We are now performing an updated version of a registry study of LAM using a nation-wide sample from China (LAM-China, ClinicalTrials.gov\# 03193892). Patients in the LAM-China study will be evaluated annually.

\section{Conclusion}

Sirolimus is effective in stabilizing or improving pulmonary function, blood oxygen levels, exercise capacity, and quality of life in patients with LAM. Sirolimus is effective in the treatment of LAM-related chylothorax. Sirolimus also decreases the VEGF-D levels, a biomarker of LAM disease severity. Sirolimus is safe in long-term use with a median follow-up of 2.5 years. A dose of sirolimus between 5 and $9.9 \mathrm{ng} / \mathrm{mL}$ is appropriate.

\section{Abbreviations}

6MWD: 6-min walking distance; AML: Angiomyolipomas; DLco: Diffusing

capacity for carbon monoxide; ERS: European Respiratory Society;

$\mathrm{FEV}_{1}$ : Forced expiratory volume in $1 \mathrm{~s}$; FVC: Forced vital capacity;

LAM: Lymphangioleiomyomatosis; MILES: Multicenter International Lymphangioleiomyomatosis Efficacy and Safety of Sirolimus;

mTOR: Mammalian target of rapamycin; $\mathrm{P}_{(\mathrm{A}-\mathrm{a})} \mathrm{O}_{2}$ : Alveolar-arterial oxygen gradient; $\mathrm{P}_{2} \mathrm{CO}_{2}$ : Partial pressure of carbon dioxide in arterial blood; $\mathrm{P}_{\mathrm{a}} \mathrm{O}_{2}$ : Partial pressure of oxygen in arterial blood; PUMCH: Peking Union Medical College Hospital; RV: Residual volume; SGRQ: St. George's Respiratory Questionnaires; TLC: Total lung capacity; TSC: Tuberous sclerosis complex; VEGF-D: Vascular endothelial growth factor-D

\section{Acknowledgements}

The authors are grateful to the patients for their contribution.

\section{Funding}

This work was supported by the National Key Research and Development Program of China (2016YFC0901502), Beijing Municipal Science and Technology Project (Z151100003915126), and the National Natural Science Foundation of China (81570061)

Availability of data and materials

The datasets used and analyzed during the current study are available from the corresponding author. 


\section{Authors' contributions}

YZ and LS were involved in the study design, data analysis and manuscript drafting. WX, XW, JW, XL participated in clinical evaluation of the patients. WZ participated in radiology evaluation of the patients. XT and YY participated in clinical evaluation and manuscript drafting. KFX were involved in the study design, performed clinical evaluation of the patients and critical evaluation of the manuscript. All authors read and approved the final manuscript.

\section{Ethics approval and consent to participate}

The study was part of the LAM registry study of PUMCH. The protocol was approved by the Ethical Committee of Peking Union Medical College Hospital (S-379). All subjects included in this study signed informed consent documents

\section{Consent for publication}

Consent for publication was obtained from all participants.

\section{Competing interests}

The authors declare that they have no competing interests.

\section{Publisher's Note}

Springer Nature remains neutral with regard to jurisdictional claims in published maps and institutional affiliations.

\section{Author details}

${ }^{1}$ Department of Respiratory Medicine, Peking Union Medical College Hospital, Beijing, China. ${ }^{2}$ Department of Radiology, Peking Union Medical College Hospital, Beijing, China.

\section{Received: 7 November 2017 Accepted: 12 February 2018}

Published online: 20 February 2018

\section{References}

1. Thway K, Fisher C. PEComa: morphology and genetics of a complex tumor family. Ann Diagn Pathol. 2015;19:359-68.

2. Kristof AS, Li PZ, Major P, Landry JS. Lymphangioleiomyomatosis and tuberous sclerosis complex in Quebec: prevalence and health-care utilization. Chest. 2015:148:444-9.

3. Harknett EC, Chang WYC, Byrnes S, Johnson J, Lazor R, Cohen MM, et al. Use of variability in national and regional data to estimate the prevalence of lymphangioleiomyomatosis. QJM. 2011;104:971-9.

4. Taveira-DaSilva AM, Stylianou MP, Hedin CJ, Hathaway O, Moss J. Decline in lung function in patients with Lymphangioleiomyomatosis treated with or without progesterone. Chest. 2004;126:1867-74.

5. McCormack FX, Inoue Y, Moss J, Singer LG, Strange C, Nakata K, et al. Efficacy and safety of sirolimus in lymphangioleiomyomatosis. N Engl J Med. 2011:364:1595-606.

6. Glasgow CG, Steagall WK, Taveira-Dasilva A, Pacheco-Rodriguez G, Cai X, ElChemaly $\mathrm{S}$, et al. Lymphangioleiomyomatosis (LAM): molecular insights lead to targeted therapies. Respir Med. 2010;104:S45-58.

7. Saxton RA, Sabatini DM. mTOR signaling in growth, metabolism, and disease. Cell. 2017;168:960-76.

8. Yao J, Taveira-DaSilva AM, Jones AM, Julien-Williams P, Stylianou M, Moss J. Sustained effects of sirolimus on lung function and cystic lung lesions in lymphangioleiomyomatosis. Am J Respir Crit Care Med American Thoracic Society. 2014;190:1273-82.

9. Ando K, Kurihara M, Kataoka H, Ueyama M, Togo S, Sato T, et al. Efficacy and safety of low-dose sirolimus for treatment of lymphangioleiomyomatosis. Respir Investig. 2013;51:175-83.

10. Taveira-DaSilva AM, Hathaway O, Stylianou M, Moss J. Changes in lung function and chylous effusions in patients with lymphangioleiomyomatosis treated with sirolimus. Ann Intern Med. 2011;154:797-805.

11. Taveira-DaSilva AM, Jones AM, Julien-Williams P, Stylianou M, Moss J. Longterm effect of sirolimus on serum VEGF-D levels in patients with lymphangioleiomyomatosis. Chest. 2018:153(1):124-32.

12. Hecimovic A, Jakopovic M, Pavlisa G, Jankovic M, Vukic-Dugac A, Redzepi G, et al. Successful treatment of pulmonary and lymphatic manifestations of lymphangioleiomyomatosis with sirolimus. Lymphology. 2015;48:97-102.

13. Freitas CSG, Baldi BG, Araújo MS, Heiden Gl, Kairalla RA, Carvalho CRR. Use of sirolimus in the treatment of lymphangioleiomyomatosis: favorable responses in patients with different extrapulmonary manifestations. J Bras Pneumol. 2015:41:275-80.

14. Davies DM, de Vries PJ, Johnson SR, McCartney DL, Cox JA, Serra AL, et al. Sirolimus therapy for angiomyolipoma in tuberous sclerosis and sporadic lymphangioleiomyomatosis: a phase 2 trial. Clin Cancer Res American Association for Cancer Research. 2011;17:4071-81.

15. Johnson SR, Cordier JF, Lazor R, Cottin V, Costabel U, Harari S, et al. European Respiratory Society guidelines for the diagnosis and management of lymphangioleiomyomatosis. Eur. Respir. J. European respiratory. Society. 2010;35:14-26.

16. Wanger J, Clausen JL, Coates A, Pedersen OF, Brusasco V, Burgos F, et al. Standardisation of the measurement of lung volumes. Eur. Respir. J. European respiratory Society. 2005;26:511-22.

17. ATS Committee on Proficiency Standards for Clinical Pulmonary Function Laboratories. ATS statement: quidelines for the six-minute walk test. Am. J. Respir. Crit. Care Med. American Thoracic Society. 2002;166:111-7.

18. Jones PW, Quirk FH, Baveystock CM. The St George's respiratory questionnaire. Respir Med. 1991:85:25-31.

19. Vestbo J, Edwards LD, Scanlon PD, Yates JC, Agusti A, Bakke P, et al. Changes in forced expiratory volume in 1 second over time in COPD. N Engl J Med. 2011;365:1184-92.

20. McCormack FX, Gupta N, Finlay GR, Young LR, AM T-DS, Glasgow CG, et al. Official American Thoracic Society/Japanese respiratory society clinical practice guidelines: Lymphangioleiomyomatosis diagnosis and management. Am J Respir Crit Care Med. 2016;194:748-61.

21. Neurohr C, Hoffmann AL, Huppmann P, Herrera VA, Ihle F, Leuschner S, et al. Is sirolimus a therapeutic option for patients with progressive pulmonary lymphangioleiomyomatosis? Respir Res BioMed Central. 2011;12:66.

22. Xu K-F, Wang L, Tian X-L, Gui Y-S, Peng M, Cai B-Q, et al. The St. George's respiratory questionnaire in Lymphangioleiomyomatosis. Chin Med Sci J. 2010;25:140-5.

23. Swigris JJ, Lee H-S, Cohen M, Inoue Y, Moss J, Singer LG, et al. St. George's respiratory questionnaire has longitudinal construct validity in Lymphangioleiomyomatosis. Chest. 2013;143(6):1671-8.

24. Barrera P, Simons SO, Luijk B, Wessels MJC, Heijdra YF. Efficacy of sirolimus therapy for chylous effusions in lymphangioleiomyomatosis. Ann Am Thorac Soc. American Thoracic Society. 2013;10:408-9.

25. Chachaj A, Drozdz K, Chabowski M, Dziegiel P, Grzegorek I, Wojnar A, et al. Chyloperitoneum, chylothorax and lower extremity lymphedema in woman with sporadic lymphangioleiomyomatosis successfully treated with sirolimus: a case report. Lymphology. 2012:45:53-7.

26. Ellender CM, Williams TJ, Gooi J, Snell GI, Whitford HM. Management of refractory chylothorax in pulmonary lymphangioleiomyomatosis. Respirol Case Rep. 2015;3:72-4

27. Ohara T, Oto T, Miyoshi K, Tao H, Yamane M, Toyooka S, et al. Sirolimus ameliorated post lung transplant chylothorax in lymphangioleiomyomatosis. Ann Thorac Surg. 2008:86:e7-8.

28. Rozenberg D, Thenganatt J. Dramatic response to sirolimus in lymphangioleiomyomatosis. Can Respir J Hindawi Publishing Corporation. 2013:20:413-4

29. Takada T, Mikami A, Kitamura N, Seyama K, Inoue Y, Nagai K, et al. Efficacy and safety of long-term Sirolimus therapy for Asian patients with Lymphangioleiomyomatosis. Ann Am Thorac Soc American Thoracic Society. 2016:13:1912-22.

30. Bee J, Fuller S, Miller S, Johnson SR. Lung function response and side effects to rapamycin for lymphangioleiomyomatosis: a prospective national cohort study. Thorax. 2017;0:1-7. 